\title{
Revue Incidence, Le chemin du rite : autour de l'œuvre de Michel Carty
}

Paris, Éditions du Félin, 2010, 402 p.

\section{Mustapha Naïmi}

\section{(2) OpenEdition}

\section{Journals}

Édition électronique

URL : http://journals.openedition.org/assr/23557

DOI : $10.4000 /$ assr.23557

ISSN : $1777-5825$

\section{Éditeur}

Éditions de l'EHESS

Édition imprimée

Date de publication : 31 décembre 2011

Pagination : 265

ISBN : 9782713223273

ISSN : 0335-5985

\section{Référence électronique}

Mustapha Naïmi, « Revue Incidence, Le chemin du rite : autour de l'œuvre de Michel Carty », Archives de sciences sociales des religions [En ligne], 156 | octobre-décembre 2011, document 156-96, mis en ligne le 17 février 2012, consulté le 21 septembre 2020. URL : http://journals.openedition.org/assr/ 23557 ; DOI : https://doi.org/10.4000/assr.23557

Ce document a été généré automatiquement le 21 septembre 2020

(C) Archives de sciences sociales des religions 


\title{
Revue Incidence, Le chemin du rite : autour de l'œuvre de Michel Carty
}

Paris, Éditions du Félin, 2010, 402 p.

\author{
Mustapha Naïmi
}

\section{RÉFÉRENCE}

Revue Incidence, Le chemin du rite : autour de l'œuvre de Michel Carty, Paris, Éditions du Félin, 2010, 402 p.

1 Les auteurs qui participent à ce numéro de la revue Incidence appartiennent à des domaines différents du champ de la recherche : anthropologie, philosophie, sociologie, psychanalyse, histoire, littérature, etc. Ils rendent un hommage à l'ethnologue africaniste Michel Carty, disparu le 18 août 2008. Enseignant-chercheur à l'EPHE, le centre de gravité de ses recherches se situe dans l'analyse des énoncés rituels, d'abord chez les Gourmantché mais aussi, de manière comparative, dans d'autres populations de l'aire voltaïque. Ce volume rassemble les contributions et les témoignages des collègues de Michel Carty qui se sont donné pour tâche de réfléchir sur ses apports essentiels à l'ethnologie. Certaines contributions se sont nourries des thèmes abordés dans ses textes. C'est le cas de Danatou Liberski-Bagnoud sur la divination et les conditions d'émergence de la parole oraculaire, celle de Chiara Alfieri sur la divination par le placenta et de Sada-Mamadou Ba sur le felngo des peuls. Certains auteurs reviennent sur d'autres recherches de Michel Carty, celles qu'il a menées sur le sacrifice (Alfred Adler propose une lecture du «suaire du chef », Françoise DumasChampion une étude comparative des sacrifices pratiqués par les Réunionnais des plantations) et sur le territoire et la fondation (Odile Journet-Diallo étudie les enjeux du meurtre et de la prédation quant aux rapports que les Joola-Kujamaat entretiennent avec les puissances qui les lient à leur territoire, Susan Drucker-Brown met en évidence la double conception du temps présente dans les chants d'éloge des tambourinaires manuprusi). Enfin, en décelant dans la description durkheimienne de l'intichiuma une 
logique propre au rituel, Bruno Karsenti propose une relecture de l'histoire de l'anthropologie religieuse qui fait directement écho au programme théorique de M. Carty. À côté de ces textes, qui prolongent ou discutent les recherches de M. Carty, divers témoignages sont présentés dans ce numéro d'Incidence dans l'espoir qu'ils permettent à ceux qui n'ont pas eu le privilège de le connaître de mieux comprendre son itinéraire et sa démarche intellectuelle. 